\title{
Designing for Collective Remembering
}

\section{Corina Sas}

Computing Department

Lancaster University

Lancaster, LA1 4WA, UK

c.sas@lancaster.ac.uk

Alan Dix

Computing Department

Lancaster University

Lancaster, LA1 4WA, UK

c.sas@lancaster.ac.uk

\author{
Abstract \\ This paper outlines the \\ rationale for the \\ workshop topic and \\ offers an overview of its \\ objectives.
}

\section{Keywords}

Collective memories,

episodic memory,

memory technology,

interaction design.

\section{ACM Classification} Keywords

H. 5 Information

interfaces and

presentation (e.g.

$\mathrm{HCl}$ ): H.5.2 User

Interfaces and H.5.3

Group and Organization

Interfaces.

\section{Introduction}

The role of past experiences and their recollection cannot be overestimated. Whether personal or collective, memories enable people to understand past experiences, learn from them and build a new perspective of their lives. Thus, memories are valuable tools in maintaining and enriching people's sense of identity.

One way to provide better support for the recall of our memories is to externalize, capture and store them. In the past, people used diaries, photographs or artifacts to serve as memory prompts. Nowadays, digital image, sound and video collections make the process of storing and recalling memories easier. Moreover, this makes the memories remotely accessible.

When memories are shared, the richness of the experience associated with them is shared as well. In this way, those who have access to others' memories develop their own memories about the same experience. When technologies are used as a media for accessing the shared experience, the memories that people build are not firsthand experiences but prosthetic memories [8]. Immersion and sense of presence account largely for the richness and authenticity of prosthetic memories [9]. 
The paper is organized along three sections introducing the relevant aspects related to collective memories and memory technology, together with a description of workshop goals.

\section{Collective Memories}

Although the common approaches to the study of memory-related processes were traditionally focused on the individual, the social character of memory has a long standing acknowledgment in the humanities. In fact, in the last two decades there has been a growing interest in collective memory which spans psychology, history, communication and philosophy [2]. This wave of memory research in these disciplines provides support and claims feedback from human-computer interaction and design fields.

When memories relate to significant events impacting on an entire group or community and are shared amongst that group, they become collective. Each individual has their own memories about particular aspects of reality in their life, but it is the event itself that triggers and causes these memories to be gathered, so that each personal memory becomes a facet of the collective one. While personal memories enhance an individual sense of identity, collective memories enhance a community sense of identity [6], [13].

Since collective memories carry the emotional print associated with the original experiences, their recall is almost always emotionally charged. This aspect is particularly enhanced by the process of sharing memories with other people. In addition, the act of sharing individual memories can alter the initial emotional print that an individual holds before his/her memories become collective. Such memories are usually rich, and can be best externalized through narratives [13].

\section{Memory Technologies}

The work for designing and developing memory technology can be broadly seen as covering two distinct areas: personal memory archives and computer supported collaborative work (CSCW).

Much research has focused on investigating ways of capturing and sharing autobiographical or personal memories. The impact of episodic memories on one's life has been largely acknowledged by research into (i) the design and development of technologies for capturing the significant experiences or memories [11] or (ii) the continuous capturing of lifelong personal experience [5]. When designing and developing such systems we need to address the challenges arising from the richness and narrative aspects of episodic memories.

The research on technologies for group memories has been triggered by the demands of CSCW [3]. Efforts have been made in capturing and organizing memories belonging to the experts in an organization with the purpose of providing a tool for supporting organizational goals [1]. Such repositories of expertise are focused mainly on memories for procedural knowledge.

Collective memories can be captured on an individual basis, but experimental studies suggest that groups outperform individuals in memory performance [7]. 
Somewhere in between personal episodic memories and procedural group knowledge there have been attempts to augment human memory [4] particularly by providing electronic memory aids [12].

Less work has focused on designing usable systems for gathering collective episodic memories. Such technologies for memory will support the development of digital lieux de mémoire [10] which will have a fourfold benefit. First, since digital memories can be stored and replicated, they transcend both time and space, and so can be accessed by users anytime, anywhere. Second, building on this, sharing memories is an interactive experience which can connect people. Third, sharing memories facilitates an emotional reassessment through the alteration of the emotional print associated with individual memories. Fourth digital memories archives can support both the process of capturing the group memories and the subsequent access to them. These corpora of shared experiences are valuable learning resources for users' reflection on the past and planning for the future. Furthermore, researchers can use these corpora to understand human behavior and social events.

The benefits of developing such memory technologies can be exceeded only by its challenges, and this workshop is designed to address some of them.

\section{Workshop Objectives}

This one day workshop will offer an interdisciplinary forum of discussion for both practitioners and academic researchers interested in designing technology for collective remembering. It will span research fields like interactive design, $\mathrm{HCl}$, computer science, sociology, anthropology and information science. The workshop will facilitate discussions aimed at the development of a set of guidelines for designing systems for collective remembering: collecting, storing and sharing memories. This includes designing for the experience of sharing one's own memories, and for the experience of enjoying others' memories.

The workshop will serve as a forum for exchanging ideas and aims to address the following questions:

- What are the most important user aspects when designing for collective remembering?

- In designing for collective remembering, what is the best way of enacting memories?

- In designing for collective remembering, what is the best way of "consuming" memories already externalized and captured?

- What is the role of sense of presence in designing for collective remembering, and how can it be exploited?

- How can interactivity enhance the technology for remembering?

- Which are the challenges of usability studies for collective remembering systems?

- How can issues like privacy, ownership, and control over ones' memories be addressed?

- What are the ethical issues regarding the usage of a corpora of people's memories?

Scope

The workshop accepts original contributions relating (but not limited) to:

- designing technology for triggering, capturing, storing and sharing collective memories

- designing for engagement and enrichment of emotional aspects associated with accessing and sharing memories

- design guidelines for technologies that memory gather, store and share memories 
- human factors in the memory gathering and sharing processes

- methods and instruments for the usability of memory technology

- multi-modal interaction and multimedia for memory technology

- pervasive and mobile technology as memory technology

- social aspects related to memory technologies: sharing, sense of community, group identity

- psychological aspects related to memory technology: privacy, ownership, anonymity

- learning from collective memories, e.g. providing children with access to collective memories and to the lessons associated with them.

\section{References}

[1] Ackerman, M.S. Augmenting organizational memory: a field study of answer garden. ACM Transactions on Information Systems 16, 3 (1998), 203-224.

[2] David, M. and Edwards, D. (eds). Collective Remembering. Sage, London, 1990.

[3] Cole, R. and Xiao, Lu. A Review of Human Memory, SIGCHI Bulletin Archive 37, 2 (2005).

http: //bulletin2.sigchi.org/archive/2005.2/book_review _human_memory/index.html

[4] Fass, A., Forlizzi, J. and Pausch, R. MessyDesk and MessyBoard: two designs inspired by the goal of improving human memory. Proc. Designing interactive systems: processes, practices, methods, and techniques, ACM Press, (2002), 303-313.
[5] Gemmell, J and Sundaram, H. (eds.) Proc Continuous archival and retrieval of personal experiences, ACM Press, (2004).

[6] Halbwachs, M. The Collective Memory [1951]. Harper and Row, New York and London, 1980.

[7] Hartwick, J., Sheppard, B. H, \& Davis, J. H. Group remembering: Research and implications. In R. A Guzzo (Ed.), Improving group decision making in organizations. Academic Press, San Diego, CA, (1982), 41-72.

8] Landsberg, A. America, the Holocaust, and the Mass Culture of Memory: Toward a Radical Politics of Empathy. New German Critique 71 (1997), 63-86.

[9] Lombard, M. and Ditton, T. At the heart of it all: The concept of presence. Journal of ComputerMediated Communication 3, 2 (1997)

http://jcmc.indiana.edu/vol3/issue2/lombard.htm|

[10] Nora, P. (ed). Les Lieux de memoire. Paris: Editions Gallimard, 1984-1992. (trans. Realms of Memory: The Construction of the French Past.) Columbia University Press, New York, 1996-1998.

[11] Stevens, M.M., Abowd, G.D., Truong, K.N., Vollmer, F. Getting into the Living Memory Box: Family archives \& holistic design. Personal and Ubiquitous Computing 7, 4 (2003), 210-216.

[12] Szymkowiak, A., Morrison, K., Gregor, P., Shah, P. Evans, J., Wilson. A. A memory aid with remote communication using distributed technology. Personal and Ubiquitous Computing 9, 1 (2005), 1-15.

[13] Wertsch. J. Voices of Collective Remembering Cambridge University Press, Cambridge, 2002. 